\title{
Airway fire injury during rigid bronchoscopy in a patient with a silicon stent
} -A case report-

\author{
Ji-Young Lee ${ }^{1}$, Chan Beom Park ${ }^{2}$, Eun-Jeong Cho ${ }^{1}$, Chang Jae Kim , Jun Seuk Chea ${ }^{1}$, Byung Ho Lee , \\ Jin-Ook Kim ${ }^{1}$, and Mee Young Chung ${ }^{1}$
}

Departments of ${ }^{1}$ Anesthesiology and Pain Medicine, ${ }^{2}$ Thoracic \& Cardiovascular Surgery, College of Medicine, The Catholic University of Korea, Seoul, Korea

Therapeutic bronchoscopy is widely employed as an effective first-line treatment for patients with central airway obstructions. Airway fires during rigid bronchoscopy are rare, but can have potentially devastating consequences. Pulmonologist and anesthesiologist undertaking this type of procedure should be aware of this serious problem and be familiar with measures to avoid this possibly fatal complication. We report the case of a 24-year-old patient with a silicone stent who experienced an electrocautery-induced airway fire during rigid bronchoscopy. (Korean J Anesthesiol 2012; 62: 184-187)

Key Words: Airway fire, Electrocautery, Rigid bronchoscopy, Silicone stent.

Central airway obstruction can be caused by malignant or benign tumors, extrinsic compression, post-intubation trachea injuries, tracheabronchomalacia, or sequelae following tracheostomy [1]. In the past, many patients with central airway obstructions would have been regarded either as inoperable or only manageable by surgery, with high morbidity and significant mortality. Nowadays, laser resection, coagulation by electrocautery or argon plasma, balloons and bougies allow for palliative techniques to alleviate central airway obstruction. Insertion of a tracheobronchial stent using rigid bronchoscopy can also provide symptomatic relief [2]. Although patients can be managed using fiberoptic bronchoscopy under local anesthesia, rigid bronchoscopy under general anesthesia provides a safer and more controlled environment within which to manage patients presenting with airway problems [3]. However, anesthetic management during these procedures can be challenging since the obstructed airway must be accessible to the anesthesiologist and bronchoscopist simultaneously. Complications of rigid bronchoscopy during the process of stent insertion include respiratory failure, airway perforation, mucosal damage, hemorrhage, post-manipulation airway edema, and potential airway loss at the end of the procedure [4]. In particular, fire in the upper airway is rare, but potentially fatal [5].

We experienced a case of an electrocautery-ignited fire in the

Received: April 8, 2011. Revised: 1st, June 13, 2011; 2nd, June 28, 2011; 3rd, July 11, 2011. Accepted: July 18, 2011.

Corresponding author: Mee Young Chung, M.D., Department of Anesthesiology and Pain Medicine, College of Medicine, The Catholic University of Korea, St. Paul's Hospital, 620-56, Jeonnong-dong, Dongdaemoon-gu, Seoul 130-109, Korea. Tel: 82-2-958-2099, Fax: 82-2-9670235, E-mail: jhjs0806@catholic.ac.kr

(c) This is an open-access article distributed under the terms of the Creative Commons Attribution Non-Commercial License (http:// creativecommons.org/licenses/by-nc/3.0/), which permits unrestricted non-commercial use, distribution, and reproduction in any medium, provided the original work is properly cited. 
airway during rigid bronchoscopy being performed to address tracheal stenosis caused by granulation tissue on a silicone stent.

\section{Case Report}

A 24-year-old man, $175 \mathrm{~cm}$ and $80 \mathrm{~kg}$, had experienced unconsciousness as a result of ammonia gas intoxication while cleaning a septic tank. Mechanical ventilation was maintained for five days following a tracheostomy. Once the tracheostomy tube was removed the tracheostomy site was repaired three days later. The patient subsequently experienced tracheal stenosis and a silicone stent (diameter $12 \mathrm{~mm}$, length $4.5 \mathrm{~cm}$ ) was inserted $3 \mathrm{~cm}$ distal to the vocal cords under rigid bronchoscopy. Two months later, tracheal dilation with eletrocautery was performed several times under general or local anesthesia as the trachea had become narrowed by fibrous tissue covering the stent. When admitted to the operating room for dilatation of tracheal stenosis with rigid bronchoscopy under general anesthesia on this occasion, the patient's blood pressure and heart rate were 135/75 $\mathrm{mmHg}$ and 94 beats/min, respectively and oxygen saturation by pulse oximeter was $96 \%$. General anesthesia was induced with propofol (target plasma concentration $3.0-6.0 \mu \mathrm{g} / \mathrm{ml}$ ) and remifentanil (target plasma concentration $3.0-4.0 \mathrm{ng} / \mathrm{ml}$ ) using a target controlled infusion pump (Orchestra Infusion Workstation, V03.OOS-1, Fresenius Vial, France). After rocuronium $0.6 \mathrm{mg} / \mathrm{kg}$ was administered, a rigid bronchoscope was inserted. Ventilation was mechanically controlled at a tidal volume of $600 \mathrm{ml}$ and a respiratory rate of 15 breaths/min with $4 \mathrm{~L} / \mathrm{min}$ of air and $1.5 \mathrm{~L} / \mathrm{min}$ of oxygen. For maintenance anesthesia, the patient received total intravenous

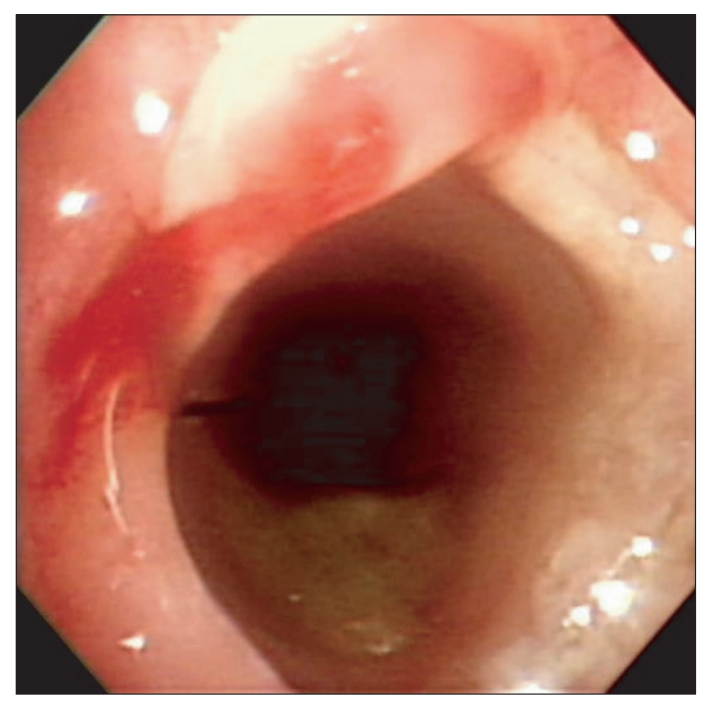

Fig. 1. Rigid bronchoscopy showing the obstructed airway with silicone stent before the fire. anesthesia (TIVA) with propofol (target plasma concentration $3.0-6.0 \mu \mathrm{g} / \mathrm{ml}$ ) and remifentanil (target plasma concentration $1.0-4.0 \mathrm{ng} / \mathrm{ml}$ ). During the procedure, blood pressure and heart rate were $140 / 80-150 / 100 \mathrm{mmHg}$ and $90-110$ beats/ min, respectively. Oxygen saturation by pulse oximeter, end tidal $\mathrm{CO}_{2}$ and airway pressure were 95-100\%, 35-45 $\mathrm{mmHg}$, and $30-35 \mathrm{cmH}_{2} \mathrm{O}$, respectively.

Granulation tissue and the upper part of the stent were visualized beyond the vocal cords using rigid bronchoscopy (Fig. 1). Granulation tissue was removed and coagulation initiated with electrocautery at which time a loud popping sound was heard and smoke was seen leaking from the mouth and bronchoscope. The stent was charred and the mucosa of the lower airway, including the main bronchi, was covered with gray dust (Fig. 2). The stent and grey dust in the airway were removed and the area irrigated with saline. Following tracheal intubation, the patient was transferred to the intensive care unit for mechanical ventilation. He was treated with $\mathrm{N}$-acetylcysteine, ipratropium bromide, and salbutamol nebulizers, hydrocortisone, and antibiotics. The next day the patient was weaned from mechanical ventilation with an oxygen saturation of $95-99 \%$ according to pulse oximetry.

The patient complained of respiratory discomfort on postoperative day three. His oxygen saturation had decreased to $86 \%$ and his respiratory rate had increased to $30-40$ breaths $/ \mathrm{min}$. Emergency fiberoptic and rigid bronchoscopy under general anesthesia was performed. The bronchus and bronchial tree were found to be obstructed by pseudomembrane and exudate (Fig. 3). These obstructions were removed with bronchial forceps and a tracheostomy was performed. Thereafter, fiberoptic and rigid bronchoscopy were performed once or twice per week to

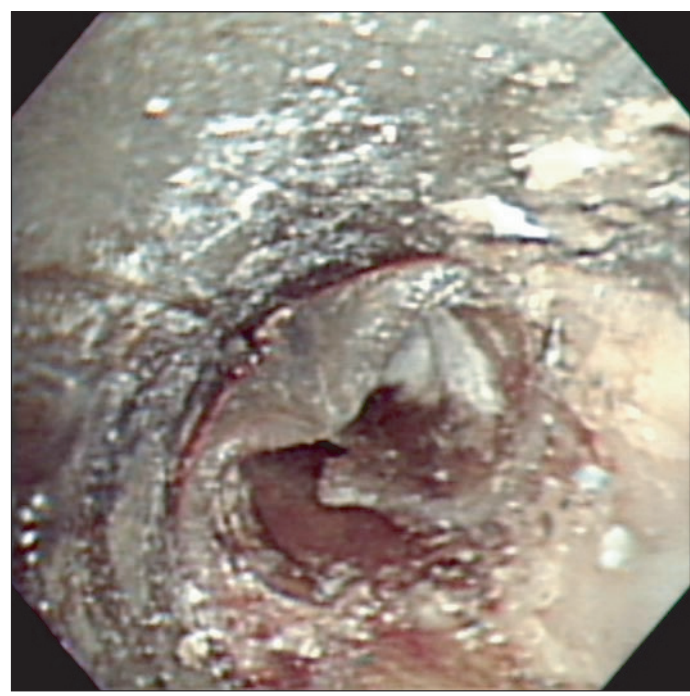

Fig. 2. After the fire, the ignited airway with charred stent. 


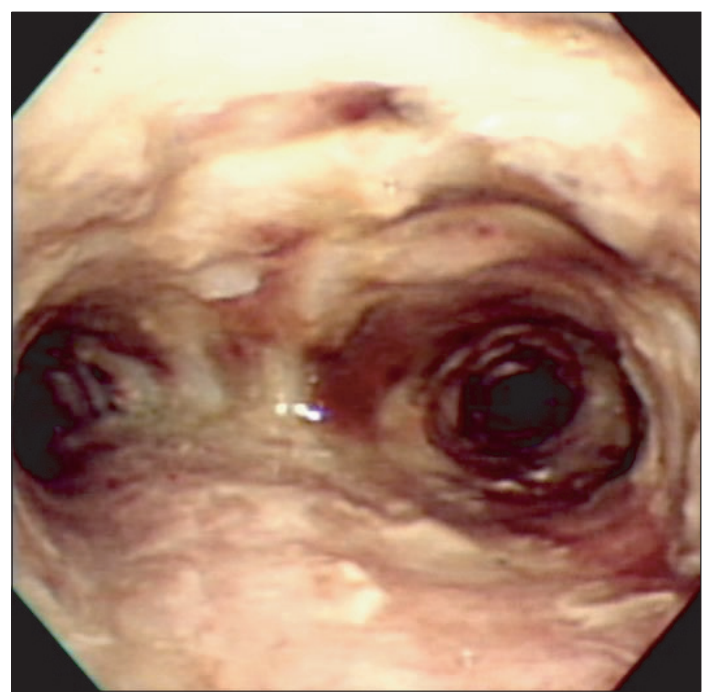

Fig. 3. The main bronchi obstructed with pseudomembrane and exudate.

remove granulation tissue and exudate; however, the patient did not improved and was eventually transported to another hospital for lung transplantation.

\section{Discussion}

To manage intrinsic airway occlusion, interventional pulmonologists require tools to mechanically remove obstructions and tools for hemostasis to control bleeding associated with tissue disruption. Each technique has its own merits and limitations. Treatment choice is usually based on various factors, including clinical presentation, the expertise of the bronchoscopist, anesthetic care, and the technical facilities of each hospital [6].

$\mathrm{Nd}$ :YAG laser is the most popular coagulation technique used due to its enormous heat sink effect. However, deep tissue coagulation may not always be preferable due to the vicinity of major vessels in the central airways and the disrupted anatomy following previous treatments such as surgical resection or chemotherapy [7].

Electrocautery, on the other hand, is easy and simple to use requiring no goggles or coverage of reflecting surfaces, and runs on much less electrical energy. Complicated and expensive techniques such as lasers have not been shown to be clinically superior to this straightforward technique. Electrocautery has also proven to be effective in treating benign and low grade malignant lesions such as intraluminal typical bronchial carcinoid. The success rate using this method has been $70-$ $80 \%$, which is comparable to other debulking techniques $[6,7]$.

Airway stents are used to palliate the effects of large airway obstructions. Stent-associated complications include migration, retained secretions, colonization of stent material, stent fracture, and development of granulation tissue [8]. In particular, granulation tissue formation at stent edges can significantly narrow the internal lumen. Our patient had undergone bronchoscopy with eletrocautery several times to remove granulation tissue at the edges of his silicone stent which had led to tracheal stenosis. Removal of this granulation tissue is not easy as it tends to bleed heavily and the use of laser or electrocautery resection is contraindicated to some extent because the stent material is flammable, especially with an inspired oxygen fraction exceeding 40\% [9]. Scherer [9] reported that stents could be easily ignited in the presence of blood or mucus in an experimental study. We suppose that blood or mucus around the stent can also affect the acceleration of fire in an oxygen rich environment even though the coagulation mode is used for only a short time.

Fires in the operating room continue to be an occasional hazard, especially during airway operations. Most fires are evanescent and cause no harm, but sometimes, unfortunately, they prove fatal [10]. After an airway fire, airway edema, inflammation, mucosal necrosis, and the presence of soot and charring in the airways can be seen upon bronchoscopic examination. In addition, the ciliary transport function can be damaged, which is considered to be part of the reason for airway obstruction and the accumulation of secretions [5]. Nakae et al. [11] described that failure to clear casts could be fatal, especially if they obstruct the main bronchi. The casts consist of fibrin, neutrophils, mucus, and epithelial cell debri, and this material may occlude the lumen of the airway promoting atelectasis, pneumonia, and barotraumas. In this case, the main bronchi and bronchiole were also covered with ignited dust. After irrigation with saline, the airway was edematous and suffered mucosal necrosis due to the thermal injury. As a result of obstruction of the main bronchi and bronchiole due to pseudomembrane, mucus, and secretions by postoperative day three, dyspnea and hypoxemia developed.

The three elements involved in airway fires are fuel (e.g. endotracheal tube, drapes, swabs, alcohol solutions, vaporized adipose tissue), an oxidizing agent (e.g. air, oxygen, nitrous oxide), and heat (e.g. diathermy, laser, static electricity, hot light bulb) [10].

The fuel source in this case was a silicone stent. Silicone or rubber is less flammable than polyvinylchloride, a component of endotracheal tubes, but can be ignited under conditions of more than $40 \%$ oxygen [9].

The cutting, coagulation, and bipolar modes of electrocautery are all known to have caused airway fires. The cutting mode of electrocautery is particularly hazardous because it generates higher temperatures than the coagulation mode. Bipolar electrocautery is recommended as being a safer option, but the risk of ignition is still present since some arcing or sparking at 
the electrode-tissue interface is possible [5]. We typically use a $40 \%$ oxygen/air mixture during rigid bronchoscopy procedures. Even when the $40 \%$ oxygen/air mixture is switched to air to reduce the oxygen concentration, the residual oxygen can ignite a fire. Hermens et al. [12] reported that endotracheal tubes could be ignited even in an atmosphere of $25 \%$ oxygen. Many patients undergoing rigid bronchoscopy are critically ill and need a high fractional inspired oxygen $\left(\mathrm{FiO}_{2}\right)$ level. When using the coagulation mode during apnea, patients also need a high $\mathrm{FiO}_{2}$ and are switched to $100 \%$ oxygen just before stopping the ventilator for a period of apnea during the procedure. This high oxygen concentration has an increased potential for starting a fire [10]. Since silicone stents are known to be a combustible material during rigid bronchoscopy, prophylactic measures to avoid fires have been recommended. The concentration of the oxidizing agent can be reduced by diluting oxygen with nitrogen (air) and/or helium, or using a self-inflating ventilation bag with room air [13]. Ho et al. [14] reported that flooding the area with carbon dioxide prevented airway fires induced by diathermy. The heat of ignition must also be considered. The cutting mode of electrocautery should be avoided if at all possible when the surgical field is immediately adjacent to an oxygen source. Bipolar electrocautery or argon plasma coagulation can be used at a low voltage for a short period [13]. It is also helpful to remove blood or mucus by suction prior to using laser or electrocautery.

In the case of a fire, the oxygen supply should be disconnected immediately, and then bronchoscopy performed to remove dust and foreign bodies and document the degree and extent of thermal damage. Medical treatments include racemic epinephrine, a high dose of steroids, and extensive antibiotics. Repeat bronchoscopy is used to examined the degree and extend of thermal damage and casts are removed every 3-5 days following an airway fire [15].

The thermal damage to this patient consisted of second- and third-degree tracheal burns extending into both bronchi. He was treated with antibiotics, steroids, anticholinergics, and beta2 agonists, but pseudomembranes and exudates developed. Respiratory insufficiency and hypoxia were aggravated and lung transplantation was eventually considered necessary.

In conclusion, an electrocautery-induced fire can occur in patients with silicone stents during rigid bronchoscopy under
TIVA. Considering the results of the present case, interventional pulmonologists and anesthesiologists should pay more careful attention to insure prophylactic measures are followed to avoid such fires and prevent the devastating consequences which may result.

\section{References}

1. Saito Y, Imamura H. Airway stenting. Surg Today 2005; 35: 265-70.

2. Conacher ID. Anaesthesia and tracheobronchial stenting for central airway obstruction in adults. Br J Anaesth 2003; 90: 367-74.

3. Ranu H, Madden BP. Endobronchial stenting in the management of large airway pathology. Postgrad Med J 2009; 85: 682-7.

4. Slinger PD, Campos JH. Anesthesia for thoracic surgery. In: Miller's Anesthesia. 7th ed. Edited by Miller RD: Philadelphia, Churchill Livingstone. 2009, pp 1819-87.

5. Niskanen M, Purhonen S, Koljonen V, Ronkainen A, Hirvonen E. Fatal inhalation injury caused by airway fire during tracheostomy. Acta Anaesthesiol Scand 2007; 51: 509-13.

6. Sutedja G, Bolliger CT. Endobronchial electrocautery and argon plasma coagulation. Prog Respir Res 2000; 30: 120-32.

7. Bolliger CT, Sutedja TG, Strausz J, Freitag L. Therapeutic bronchoscopy with immediate effect: laser, electrocautery, argon plasma coagulation and stents. Eur Respir J 2006; 27: 1258-71.

8. Zakaluzny SA, Lane JD, Mair EA. Complications of tracheobronchial airway stents. Otolaryngol Head Neck Surg 2003; 128: 478-88.

9. Scherer TA. Nd-YAG laser ignition of silicone endotracheal stents. Chest 2000; 117: 1449-54.

10. Rogers ML, Nickalls RW, Brackenbury ET, Salama FD, Beattie MG, Perks AG. Airway fire during tracheostomy: prevention strategies for surgeons and anaesthetists. Ann R Coll Surg Engl 2001; 83: 37680.

11. Nakae H, Tanaka H, Inaba H. Failure to clear casts and secretions following inhalation injury can be dangerous: report of a case. Burns 2001; 27: 189-91.

12. Hermens JM, Bennett MJ, Hirshman CA. Anaesthesia for laser surgery. Anesth Analg 1983; 62: 218-29.

13. Bailey MK, Bromley HR, Allison JG, Conroy JM, Krzyzaniak W. Electrocautery-induced airway fire during tracheostomy. Anesth Analg 1990; 71: 702-4.

14. Ho AM, Wan S, Karmakar MK. Flooding with carbon dioxide prevents airway fire induced by diathermy during open tracheostomy. J Trauma 2007; 63: 228-31.

15. Yang MK, Lee HG, Lee SC, Kim KW, Kwak IY. A case of intratracheal fire ignited by the $\mathrm{CO}_{2}$ laser during laryngeal microscopic surgery. Korean J Anesthesiol 1991; 24: 450-3. 